\title{
Examining the Quality of Pre-school Education in Somali Regional State of Ethiopia
}

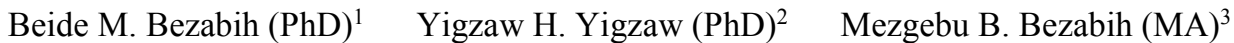 \\ 1.Assistant Professor, East African Child Development Research Institute, Jigjiga University \\ 2.Associate Professor, East African Child Development Research Institute, Jigjiga University \\ 3.Lecturer, College of Education and Behavioural Studies, Bahir Dar University
}

\begin{abstract}
The purpose of this research was to assess the quality of early childhood care and education (ECCE) environment in Somali Regional State of Ethiopia. In the study, health, nutrition, personal care routine, protective care and safety, organization and management philosophy of preschool centres, and children's experience and learning opportunities in preschool centres were examined. For the study, 37 pre-school centres were selected from five Zones of the Somali Regional State from which 44 pre-school teachers, 10 school principals and five Zonal level ECCE focal persons participated in the study. Questionnaire, interview, and an observation guide were used to collect data. The collected data was analyzed through one-sample t-test. The findings of the study indicated statistically significant differences between expected means and observed means of health, nutrition, personal care routine, protective care and safety practice, organization and management philosophy of preschool centres, and children's experience and learning opportunities in preschool centres. Finally, based on the findings, conclusions and recommendations were drawn.
\end{abstract}

Keywords: Quality; Pre-school environment; kindergarten; Somali Regional State

DOI: $10.7176 / \mathrm{JEP} / 10-22-03$

Publication date: August $31^{\text {st }} 2019$

\section{Background}

Early Childhood Care and Education (ECCE) refers to physical and psychosocial development during the first several years of life. Research suggests that most of the development of psycho-emotional, psycho-social and intelligence in children occurs before the age of seven. The first year of life is the most crucial in terms of a child's nutrition and physical growth; children who falter during this period run the risk of delayed or debilitated cognitive (mental) development. During the first two years of life, most of the growth of brain cells occurs, accompanied by the structuring of neural connections in the brain. Therefore, ECCE is recognized as one of the potential enablers to overall improvement of quality education and reduction of drop out and repetition rates in later stages of formal schooling.

Take account of this, since 1990s, ECCE has been an issue of concern for the United Nation and other development agencies and programs, including Education for All (EFA) targets, Education International (EI), and the Millennium Development Goals (MDGs). ECCE also became an agenda for many countries of the world. There is now a strong consensus on the various benefits of preschool.

The benefits of preschool are also stated in Ethiopia's Education Sector Development Program IV (ESDP IV) that through an expansion of ECCE the drop-out rate in early grades, which is very high in many Ethiopian schools, can significantly decrease. At the same time, children who have attended ECCE, more easily acquire the necessary basic reading and writing skills (MOE, 2010). Therefore, investing on preschool programs act like preventative medicine: the initial investment more than pays for itself both financially and socially.

The third Education Sector Development Program, ESDP-III (MoE, 2005) also indicated the importance of early childhood care and education program for later learning. The document states that pre-primary educational opportunity has significant importance since it introduces children to basic learning skills that are needed in primary schools and enhance their chances of success in the education system. It has been proved that educating children at an early age is more critical than at a later age (p. 41).

There are numerous evidences that show the Ethiopian government's strong attention on ECCE. In 2010, the government of Ethiopia represented by the ministries of Education, Health and Women's affairs, signed and endorsed a National Policy Framework for Early Childhood Care and Education (ECCE) to provide a holistic and comprehensive approach to the development of children from pre-natal to seven years of age. The vision of the policy is to ensure the fulfilment of every child's right to a healthy start in life, to grow in a nurturing, safe, caring and stimulating environment, and to develop to their full potential. The National Policy framed through a multisectorial structure of coordination amongst the Ministry of Education, the Ministry of Health, and Ministry of Women's Affairs.

To support the National Policy Framework, the Government of Ethiopia formulated a Strategic Operational Plan with the aim of achieving the Policy's vision by increasing access and improving the quality of ECCE services for children. The ECCE Programme will be based on 4 basic pillars of the Policy framework and strategic 
operational plan: i) Parental education, ii) Health and early stimulation iii) Preschools attached to primary schools and community-based kindergartens and iv) Community-based non-formal school readiness (MOE, 2010).

According to National ECCE Strategic Operation Plan (MOE, 2010), these 4 pillars gave birth to design the National ECCE Programme in align with the principles of the National ECCE Strategic Operational Plan which was aimed to ensure availability, equitable access to and affordability of quality ECCE services to all children. Especially, for those who are marginalized and disadvantaged like Somali Regional State that needs a close supportive systems, guidelines and interventions that ensure the quality and standardization of ECCE services and provisions.

\section{Statement of the Problem}

The Ethiopian education system has been taking a new path following the promulgation of the 1994 Education and Training Policy. Various programs and strategies are being introduced into the education system taking access, quality, equity and relevance as main areas of intervention since the last two decades. The Education Sector Development Program (ESDP) is one of such interventions with remarkable achievements.

The Federal Ministry of Education has encouraged all Regional Education Bureaus and City administration to open O'classes for all primary schools in the country both rural and urban areas. In the Education Sector Development Plan IV, Early Childhood Care and Education was recognized as one of the potential to the overall improvement of quality of education and reduction of drop out and repetition rates in later stages of formal schooling and because it leads to higher enrolments, particularly of girls. At the same time, children who have attended ECCE, more easily acquire the necessary basic reading and writing skills (MoE, 2010).

The problem of access to ECCE in Ethiopia has been raised in different forums by different agencies. According to MoE and Education Statistics Annual Abstract 2011/12 report, out of the estimated 7.51 million children of the appropriate age group (age 4-6), about 1.62 million children have been reported to have access to pre-primary education all over the country, which is very small when compared to the appropriate age group described above. Currently, the ECCE service coverage reaches $21 \%$ in considering the participation of kindergarten, O-classes and Child to child approaches. Yet the formal pre-school coverage is still very low, 5.1\% (Tirusew et al, 2009). This expansion of O-Classess in all primary schools has enabled the country to over achieve the gross enrolment rate of $34 \%$ instead of $20 \%$ that was planned (MoE, 2010).

More importantly, the national assessment survey of the status of ECCE in Ethiopia conducted in 2007 (Tirussew et al., 2009) has pinpointed a number of issues negotiating the issue of quality in the provision of ECCE in the urban Ethiopia. While preschool attendance has been rising, there is a great deal of variation in access and quality of preschool from region to region and even within region. It becomes below the national average in pastoralist areas like the Somali Region. This is because pastoralist lifestyle is manifested in a number of outcomes (e.g., school enrolment, attendance, and completion rates) (UNICEF, 2015).

A study conducted in Jigjiga town identified problems of pre-school centres that ranged from program design to classroom interaction: large numbers of students in a class; scarcity of education materials; lack of harmonized curriculum; congested and overcrowded classroom environment; shortage of educational and play materials; uncomfortable playgrounds; developmentally inappropriate (teacher-dominated and lecturing-type interaction) teaching and use of either under qualified teaching staff (Yigzaw \& Sirinabas, 2017; Beide\& Yigzaw, 2019). Hence these children and the Somali region as a whole is not able to utilize the potential advantages of quality ECCE mentioned above.

The heart of the issue is, in general, there is now a need to go beyond access and address quality of ECCE in the Somali Regional State. It should be realized that all children, without exception, have the right to quality early education. The imperative for the exercise of this right could be most urgent in the most vulnerable areas (pastoral areas) like the Somali regional state.

Thus, this research could be taken as a baseline survey of the project that seeks to address the minimal access to early childhood care education programs and the insufficient quality of it in some selected pre-school centres in the region. The purpose of this study was to: i) Investigate health, nutrition, personal care and routine practices, ii) Explore protective care and safety practices of preschool centres, iii) examine organization and management philosophy of preschool centres, iv) Explore children's experience and learning opportunities in preschool centres.

\section{Method \\ Design}

The design of this study is convergent parallel (mixed) design. As Creswell (2012) indicated, this design is useful to collect both qualitative and quantitative data concurrently. It also useful to obtain a more complete understanding of the problem from two data bases, corroborate results from different methods. In relation to this, Mertens (2005) as cited in Dorneyi (2007:149) noted, that "mixed methods have particular value when we want to examine an issue that is embedded in a complex educational and context." The author further elaborated that the mixed approach helps the researcher to obtain an adequate data as the short coming of one is compromised by the other. 


\section{Study Site}

The research was conducted in some selected Woredas in the Somali Regional State of Ethiopia, those Woredas having preschools. The Somali Region is located in the eastern part of Ethiopia and it is the second largest of nine Ethiopian regions. The region is divided into nine zones and 68 Woredas as well as four city administrations. According to the 2013 projection of population by the Central Statistical Agency (CSA, 2013), the region had a population of 5,318,000 in 2013 of which 53\% were children under the age of 18 . The population is predominately Somali (97\%) and Muslim (98\%) and mainly use Somali language as the working language (97\%). About $86 \%$ of the population lives in rural areas, and are mainly pastoralists and, to a lesser extent, Agro- pastoralists.

\section{Population and Sampling}

The study was carried out in five selected Zonal town of Somali Regional State. Namely: Shinle (Sitti town), Jerer (Deghabur town), Fafen (Jigjiga town), Gode, and Korahe (Qebridehar town). The main justification for the selection of the zones over other zones in the region was that of existence and experience in preschools programs and government "O" classes. From the selected five towns, 37 preschool centres were selected from government O-classes and private, faith based, and NGO kindergartens. In the study, 44 preschool teachers were selected through stratified and simple random sampling. Moreover, 10 interview school principals, and 5 education experts participated in the study. The total sample size was determined based on the statistical formula which was developed and published by Krejcie and Morgan (1970). The required sample size of the study subjects wereselected by using stratified random sampling technique.

\section{Data Collection Instruments The Questionnaire}

A questionnaire was prepared to collect quantitative data from the study participants in the region. Questionnaires are adequate for quantifying data and assisting researchers to collect information from participants. Moreover, questionnaires can elicit longitudinal and comparable information from a group of respondents in a short time. The questionnaire prepared for the study was divided into different themes. The first part dealt with demographic data (six items), Health, Nutrition, and Personal Care and Routine Scale (15 items), Protective Care and Safety Scale (11 items), Pre-school Organization and Management Scale (39 items), Children's Experience and Learning Opportunities Scale (35 items), Children Assessment and Outcome Measurement Scale (13 items), and Preschool Managing to Support Quality System Scale (13 items). The questionnaire was presented in four-point Likert scales: Not Applicable, Not Met, Partially Met and Fully Met.

\section{Interview}

To collect relevant data about the issue under investigation, the researchers used a semi- structured interview. A semi-structured interview helps to generate in-depth information. It also allows the researcher to access through words to an individual's constructed reality and interpretation of his or her own experience (Fontana \& Frey, 2000). The semi-structured interview format consisted of a set of open-ended questions that could encourage participants to discuss and share detail information on issues under study. Regarding this, 14 interview guide questions for zone education experts and pre-school teachers were prepared. The first 6 dealt with demographic information of interviewees and in the second part there were 8 questions.

\section{Data analysis}

The data collected via various instruments were coded, analyzed and evaluated to transform them into information which can be easily interpreted. The qualitative data were analyzed thematically which is systematically searching and arranging the interview transcripts and notes. Hence, the following steps proposed by Howitt and Cramer (2011) was followed to analyze the qualitative data. The steps were: initial familiarization with the data, initial identification of themes, looking for connection between themes, producing a table of themes, and writing up the analysis. Furthermore, inferential statistics one sample t-test was used in order to check the expected and observed value.

\section{Result}

\section{Health, Nutrition, Personal Care and Routine Practices in Preschool Centres}

As the research findings shown, there was statistically significant difference between expected mean and observed mean $(\mathrm{df}=43, \mathrm{t}=2.22, \mathrm{P}<.05)$. Specifically, the expected mean of Health, $(\mu=15)$ Nutrition $(\mu=12.5)$, Hygiene $(\mu=10)$ and Habit formation $(\mu=7.5)$ are greater than the respective observed means. This implies that with regard to health, children's height and weight was not measured regularly, health checkups were not conducted as intended, as well as heal heeds such as sleep, rest and relaxation were not available in the centre. Concerning nutrition, caregivers who were working in the centre did not have knowledge about the advantages of balanced diet and they could not ensure sufficient time for eating for children and the like as well. With regard to hygiene and habit formation, the caregivers and teachers didn't have regular check-up of personal grooming of children, 
there was no dedicated place to store food, there were no separate toilets for children, washing hands before eating and after meals were not habituated, and teachers didn't discuss these habits with parents.

\section{Protective Care and Safety Practice in Preschool Centres}

Concerning protective care and safety, the findings revealed that the expected mean of adult supervision $(\mu=7.5)$, socio-emotional protection $(\mu=5)$ and physical safety $(\mu=15)$ are greater than their respective observed means. This indicated that children were not adequately supervised at all times and encouraged to express themselves. In relation to socio-emotional protection of children, teachers/caregivers were not sensitive to the needs of children and were not providing them with emotional support. With regard to Physical safety, caregivers or teachers were not trained to provide first aid to children in case of an emergency. Besides to this, the result also depicted that ECCE centres had no preventive measures in case of fires and other natural disasters.

\section{Organization and Management Philosophy of Preschool Centres}

In relation to organizational and management philosophy, except the parental involvement $(\mu=18.5)$ sub-domain, program philosophy and methods $(\mu=15)$, documentation and records $(\mu=7.5)$, program planning $(\mu=25)$, and staffing $(\mu=20)$ were statistically significant. This implies that, the ECCE program organization and philosophy were not aligned with the vision of national ECCE policy. Coming to documentation and record, the result displayed that children's performance was not recorded well and there was no initiative on the side of teachers to motivate children to produce portfolio. Moreover, school attendance of children was not monitored regularly. The findings also indicated that age appropriate activities and free play were not provided for children by preschool teachers and this in turn led children to be less cooperative and expressive when they needed to share ideas. The result depicted that preschool teachers were not engaged in professional development activities supported with continuous training and coaching. Moreover, the teachers did not have the required educational qualification but rather come from other fields than pre-primary educations.

\section{Children's Experience and Learning Opportunities in Preschool Centres}

It's a common fact that the development of a country is determined by the quality of education a country provides. Hence, it is imperative that preschool education program and practice be stimulating, engaging and enhance children's learning and development. However, measured by using 35 items, the teaching learning process in the study area were not good as revealed by observed means being less than expected means. In other words, developmentally appropriate toys and play materials were not available, open ended play materials were not provided for children which assists them to explore the environment, time provided by the teacher for free play for children was not sufficient, materials used by the teacher were not appropriate for language development of children, manipulative activities were not provided to children and opportunities of creative activities were not delivered via teachers.

In line with this, data obtained from interview shown that interview participants of private and faith based preschool centres had knowledge about the importance of play for children but lack the necessary equipments for indoor and outdoor play. With regard this, interviewee two said that:

"If play is practiced well with appropriate materials and grounds, it helps children learn and integrate content of different subjects through recreation. Play can be used to teach certain contents like alphabets, numbers, body parts, days, weeks, months but there no supportive materials to implement it."

The interview data revealed that most teachers in the sample schools (except few private and faith based preschool centres) did not use play, music, and storytelling as teaching methods. Moreover, no separate play grounds were available for preschool children that they played along with older children in primary grades.

Concerning the role of parents, in few preschools, parents involved in different activities of the centres. But, in many other sample schools particularly government preschools, parents did not take part in preschool activities other than sending children to school. "These parents think that they fulfilled their duty as parents once they send their children to school, and they are not willing and collaborative to communicate about school issues with teachers and directors."

\section{Assessment and Outcome Measures}

Assessment, program monitoring and evaluation of early childhood care and education was measured by using 20 items. As the result portrayed, the highest composite mean score was obtained from monitoring and supportive supervision. The expected mean is greater than the observed mean so that assessment modalities performed by preschool teachers in the study area were not up to the standard. This result revealed that preschool teachers and caregivers did not observe children's learning and development, couldn't maintain portfolios of children, and developmental checklists are not made. With regard to staff assessment and development, there was no staff appraisal and work plan review system as well as feedback was not provided in accordance to policies and guidelines.

Besides, the performance of staffs was not evaluated and individual development plans was not in place to support performance improvement. The result obtained via interview revealed that practice of assessment on children's learning progress and keeping records of child progress were poor in most pre-school centres. 


\section{Conclusions}

In health and nutrition aspects, health checkups were not done and caregivers did not have knowledge about the advantages of balanced diet. Moreover, regular check-up of personal grooming of children and washing hands before eating and after meals were not customary. In addition, toilets were not separate for preschool children. In relation to protective care and safety, children were not supervised adequately as intended and, teachers or caregivers are not sensitive to the children's needs. Regarding documentation, almost in all preschools, teachers did not observe children's learning and development and couldn't maintain portfolios of children. The program's philosophy, goals, and objectives related to nature and the environment were not established and clearly articulated.

\section{Acknowledgment}

We would like to thank the Research and Community Service Vice President Office of Jigjiga University for their financial support of this research project.

\section{References}

Beide, M. \& Yigzaw H. (2019). Quality of Early Childhood Care and Education in Jigjiga, Harar and Dire-Dawa Cities of Ethiopia. International Journal of Humanities Social Sciences and Education (IJHSSE) Vol 6, No 2, $P P$ 11-21.

Creswell, J. W. (2012). Educational Research: Planning, Conducting and Evaluating Quantitative and Qualitative Research. Upper Saddle River, NJ: Pearson Education, Inc.

Dornyei, Z. (2007). Research Methods in Applied Linguistics. New York: Oxford University Press. Reviewed by Priyanvada Abeywickrama, San Francisco State University.

Fontana, A., \& Frey, J. (2005). The Interview: From neutral stance to political involvement. In N. K. Denzin \& Y. S. Lincoln (Eds), The SAGE handbook of qualitative research (pp. 695-728). Thousand Oaks, CA: Sage.

Howitt, D. \& Cramer, D. (2011). Introduction to Research Methods in Psychology ( $\left.{ }^{\text {rd }}\right)$. England, Pearson Education Ltd.

MoE (2005). Education Sector Development Programme (ESDP III). Programme Action Plan. Addis Ababa.

Krejcie, R. \& Morgan, D. (1970). Determining sample size for research activities. Educational and psychological measurement. 30, 607-610.

MoE (2010). Education Sector Development Programme (ESDP VI). Programme Action Plan. Addis Ababa.

MoE (2010). Guidelines for Early Childhood Care and Education (ECCE) in Ethiopia, Addis Ababa, Ethiopia.

MoE (2010). National Policy Frame-work for Early Childhood care and Education in Ethiopia. Addis Ababa, Ethiopia.

MoE (2010).Strategic Operational Plan for Early Childhood Care and Education (ECCE) in Ethiopia, Addis Ababa, Ethiopia.

Tirussew T., Teka Z., Belay T., Belay H. \& Demeke G. (2009).Statusof childhood care and education in Ethiopia. In Tirussew Tefera, Aklilu Dalelo,\& Mekasha Kassaye (Eds.), First International Conference on Educational Research for Development: Vol. I. (pp. 188-223). Addis Ababa: Addis Ababa University Press.

UNICEF (2015). National Equity Situation Analysis for Ethiopia. Retrieved from https://www.unicef.org/about/annualreport/files/Ethiopia_2015_COAR.pdf

Yigzaw H. \& Srinivas, A. (2017). Practices, Benefits, and Challenges of Early Childhood Care and Education in Government and Private Centers of Jigjiga City Administration. Proceeding $2^{\text {nd }}$ National Conference on Pastoral Education, and Early Childhood Care and Education, Jigjiga University. 